\title{
Reef under threat from 'bleaching' outbreak
}

\section{Carina Dennis, Sydney}

Coral experts from around the world are meeting on the Great Barrier Reef to hammer out a research strategy in response to coral 'bleaching'.

This year's episode "may turn out to be the worst bleaching event on the Great Barrier Reef in recent history", says Ove HoeghGuldberg, director of the Centre for Marine Studies at the University of Queensland, who is chairing a three-week workshop on the problem at Heron Island Research Station, 80 kilometres off the Australian mainland.

Mass coral bleaching - estimated to have destroyed about one-sixth of the world's coral colonies during the last major occurrence in 1998 — is attributed by researchers to mild increases in ocean temperature (see below).

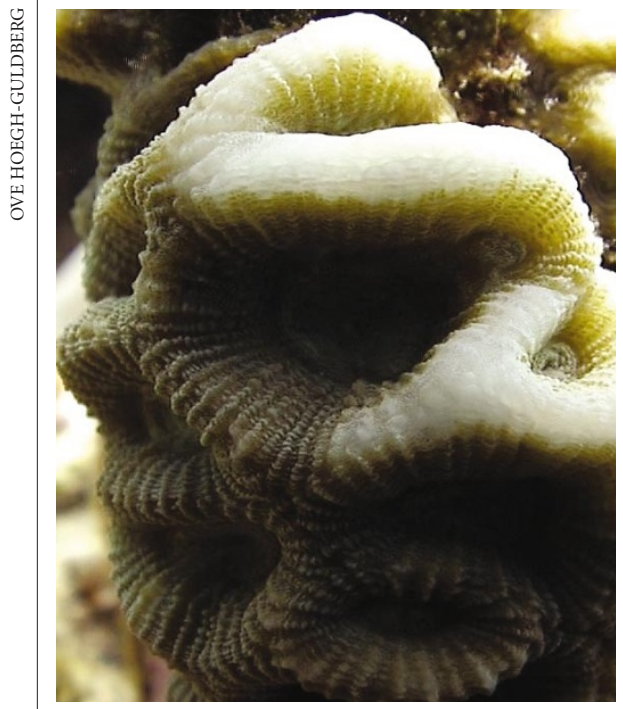

White plight: researchers fear that Australia's corals may be devastated by bleaching this year.

Coral death so far this year has been confined to reefs close to the northeast Australian coast. But according to Paul Marshall, a project manager at the Great Barrier Reef Marine Park Authority, "we are still a long way away from the end of summer and if conditions don't improve substantially, we will start to see severe bleaching and mortality over extensive areas of the reef".

Mass bleaching typically occurs when oceans are warmed by the short-term El Niño climate effect. But the 2002 bleaching is out of phase with El Niño, raising concerns that bleaching events are growing in frequency and intensity in response to climate change. "The only thing we can point at is global warming," says William Skirving of the Australian Institute of Marine Science (AIMS).
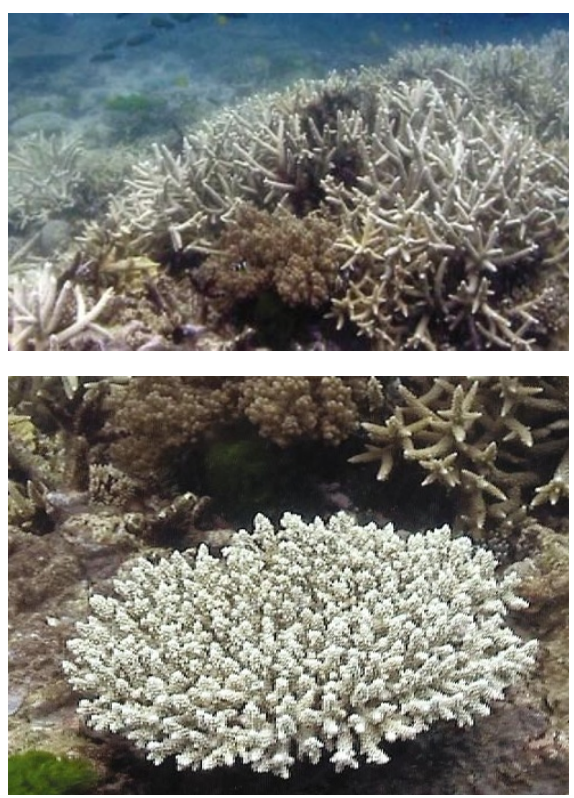

\section{How corals lighten up}

Coral bleaching occurs when stressed coral expels the symbiotic algae embedded in it. The algae give coral its brown colour, so that when the algae are Iost, the coral's calcium carbonate skeleton is exposed, rendering the reef white.

The dinoflagellate algae, known as zooxanthellae, provide the coral with energy and nutrients from their photosynthetic processes; in return, corals supply algae with essential compounds, such as ammonia and phosphate, from their waste metabolism. If the algae do not recolonize the coral tissues rapidly enough, the coral starves and dies. Incidences of local bleaching can be spurred on by a range of environmental and physiological stresses, such as heat, solar radiation, pollution, reduced salinity and changes in oxygenation. But mass bleaching is primarily caused by elevated temperatures. Corals live close to their upper thermal limit and when ocean temperatures rise $1^{\circ} \mathrm{C}$ or higher above long-term monthly averages for the warmest months, bleaching begins. Periods of still winds, clear skies and little current during the summer months on the reef are peak times for bleaching.
It is not fully understood why algae are expelled from stressed coral, but it is thought that the algae become toxic to the coral at higher temperatures. It has been proposed that elevated temperatures upset the photosynthetic metabolism in the algae, leading to the production of toxic free radicals. Researchers still debate whether it is primarily the light or dark reactions of photosynthesis that are affected.

Although coral may survive a bleaching event and recover their algae, their reproductive capacity is nonetheless impaired, resulting in long-term damage to the coral system.
Skirving's research team has developed computer models to help to predict the susceptibility of reefs to bleaching. Using information on sea-surface temperature, water depth and mixing arising from currents and tides, they can produce maps of bleaching risk, showing which parts of the reef are most vulnerable. The AIMS model complements methods developed by Al Strong of the US National Oceanic and Atmospheric Administration (NOAA), which use satellite monitoring of sea-surface temperature.

Although remote-sensing techniques are aiding the monitoring of bleaching events, biologists have limited knowledge of the physiological and ecological consequences of bleaching. "We still have a very small understanding of what proportion of bleached coral dies and what bleaching means for the ecosystem," says Marshall.

"We know the times and temperatures required to induce coral bleaching, but the question now is how much more does it take for corals to die," says Ray Berkelmans of AIMS, who is experimentally stressing corals in the laboratory to determine thresholds for bleaching. More knowledge of changes in the cellular metabolism and composition of coral during temperature shifts - for example, altered expression of 'heat-shock' proteins — could provide powerful physiological indicators for monitoring bleaching, he adds.

An important question is whether coral can adapt to increased temperatures. There has been much debate over whether coral bleaches as part of an adaptive strategy, including an exchange in Nature earlier this month (see Nature 415, 601-602; 2002). The "adaptive-bleaching hypothesis" suggests that temperature-stressed corals bleach in order to adopt more heat-tolerant varieties of algae - a scenario dismissed as overoptimistic by Hoegh-Guldberg and others.

Berkelmans says he has found little evidence of thermal adaptation after years of experiments in which he transplanted corals from cool areas to warm areas. "Even after 12 months in a warmer environment, the corals still show responses that are equivalent to that in their native cooler climate," he says.

If coral adaptation cannot keep pace with increasing sea temperatures, the survival of the world's reefs is in jeopardy. "We need to coordinate research across international boundaries," says Hoegh-Guldberg. That is the challenge for the 45 researchers gathered at the Heron Island meeting, which was convened by the Intergovernmental Oceanographic Commission of UNESCO and the World Bank. The group plans to establish a global network of researchers within six months to find answers to the mysteries that still surround coral bleaching. 